\title{
Pseudohypoaldosteronism Type 1
}

Hae Il Cheong*

Department of Pediatrics, Seoul National University Children's Hospital, Seoul, Korea

Research Coordination Center for Rare Diseases, Seoul National University Hospital, Seoul, Korea

Kidney Research Institute, Medical Research Center, Seoul National University College of Medicine, Seoul, Korea

Pseudohypoaldosteronism (PHA), a rare syndrome of systemic or renal mineralocorticoid resistance, is clinically characterized by hyperkalemia, metabolic acidosis, and elevated plasma aldosterone levels with either renal salt wasting or hypertension. PHA is a heterogeneous disorder both clinically and genetically and can be divided into three subgroups; PHA type 1 (PHA1), type 2 (PHA2) and type 3 (PHA3). PHA1 and PHA2 are genetic disorders, and PHA3 is a secondary disease of transient mineralocorticoid resistance mostly associated with urinary tract infections and obstructive uropathies. PHA1 includes two different forms with different severity of the disease and phenotype: a systemic type of disease with autosomal recessive inheritance (caused by mutations of the amiloride-sensitive epithelial sodium channel, $\mathrm{ENaC}$ ) and a renal form with autosomal dominant inheritance (caused by mutations of the mineralocorticoid receptor, MR). In the kidneys, the distal nephron takes charge of the fine regulation of water absorption and ion handling under the control of aldosterone. Two major intracellular actors necessary for the action of aldosterone are the MR and the ENaC. Impairment of the intracellular aldosterone signal transduction pathway results in resistance to the action of mineralocorticoids, which leads to PHA. Herein, ion handling the distal nephron and the clinico-genetic findings of PHA are reviewed with special emphasis on PHA type 1.

Key words: Aldosterone, Distal nephron, Epithelial sodium channel, Mineralocorticoid receptor, Pseudohypoaldosteronism

\section{Introduction}

In physiologic condition, almost 95\% of filtered $\mathrm{Na}^{+}$load is reabsorbed by proximal nephron segments, from proximal convoluted tubules to early distal convoluted tubules, and the remaining $\mathrm{Na}^{+}$load is reabsorbed in more distal nephron segments variably to maintain fine balance of body fluid and electrolytes. Aldosterone is the key regulator of the final urinary $\mathrm{Na}^{+}$and $\mathrm{K}^{+}$concentration in the distal nephron. ${ }^{\left.1{ }^{2}\right)}$

There are several kinds of disorders involving dysfunction of aldosterone. Hyperaldosteronism is a condition with an increased plasma aldosterone level either of primary or secondary causes and typically presents with volume overload and hypokalemia.
Hypoaldosteronism is an opposite condition with a decreased plasma aldosterone level accompanies hyperkalemia with/ without volume depletion. Pseudohypoaldosteronism (PHA) is another category of disorders characterized by mineralocorticoid resistance due to dysfunction of the intracellular aldosterone signaling pathway. Patients with PHA display elevated plasma aldosterone levels, hyperkalemia and metabolic acidosis. Some patients may have renal salt wasting also. PHA includes a heterogeneous, both phenotypically and genetically, group of disorders.

This paper includes brief reviews of ion transport mechanisms in the distal nephron and the clinico-genetic characteristics of PHA, with special emphasis on PHA type 1, for better understanding of

\footnotetext{
Received: 17 September 2013, Revised: 22 October 2013, Accepted: 11 November 2013, Published: 31 December 2013

*Corresponding author: Hae II Cheong, M.D., Ph.D.

Department of Pediatrics, Seoul National University Children's Hospital, 101 Daehak-Ro, Jongno-Gu, Seoul, 110-744, Korea

Tel: +82-2-2072-2810, Fax: +82-2-743-3455, E-mail: cheonghi@snu.ac.kr

Conflict of interest: We declare that we do not have any conflicts of interests.

(c) This is an open-access article distributed under the terms of the Creative Commons Attribution Non-Commercial License (http://creativecommons.org/licenses/by-nc/3.0/) which permits unrestricted non-commercial use, distribution, and reproduction in any medium, provided the original work is properly cited.

(c) Copyright 2013 by the Korean Society of Medical Genetics

www.e-kjgm.org
} 
this rather complicated disease by general clinicians and clinical nephrologists.

\section{Ion transport in the distal nephron}

The aldosterone-sensitive distal nephron includes the late distal convoluted tubules (DCT2), the connecting tubules (CNT), and the cortical and medullary collecting ducts (CCD and MCD). There are three different types of cells in the CNT and CCD; the principal cells and the $\alpha$-and $\beta$-intercalated cells. In the principal cell, $\mathrm{Na}^{+}$is reabsorbed via the electrogenic amiloride-sensitive epithelial $\mathrm{Na}^{+}$channel $(\mathrm{ENaC})$ and $\mathrm{K}^{+}$is secreted via the apical $\mathrm{K}^{+}$channels, renal outer medullary potassium channel (ROMK) and Maxi-K. The active transport at the basolateral membrane is mediated by the $\mathrm{Na}^{+}-\mathrm{K}^{+}$-ATPase. $\mathrm{Cl}^{-}$is absorbed paracellularly in principal cells and may be reabsorbed transcellularly in intercalated cells as well. The intercalated cells execute $\mathrm{K}^{+}$ reabsorption and $\mathrm{H}^{+}$and $\mathrm{HCO}_{3}{ }^{-}$secretion (Fig. 1).

Two major stimuli for aldosterone release are volume depletion and hyperkalemia. ${ }^{13,4)}$ Aldosterone plays its role by binding to its cytosolic receptor, mineralocorticoid receptor (MR). The MR, a member of the classic steroid-thyroid-retinoid nuclear receptor family, acts as ligand-dependent transcription factors that regulate a variety of physiological processes. ${ }^{5}$ Cortisol is a natural glucocorticoid and has equal affinity for the MR. The circulating level of cortisol is several-fold higher than that of aldosterone. In the distal nephron, 11ß-hydroxysteroid dehydrogenase type 2 metabolizes cortisol to the inactive cortisone allowing aldosterone unrestricted access to MR. ${ }^{6,7)}$ After binding to MR, aldosterone-MR complex translocates into the nucleus and binds to specific DNA sequences and then activates or represses the transcription of a variety of aldosterone-sensitive target genes (Fig. 2). ${ }^{8}$ Some of the target genes induce accumulation of $\mathrm{ENaC}$ at the plasma membrane and enhance the transcription and translation of ENaC subunits, basolateral $\mathrm{Na}^{+} \mathrm{K}^{+}$-ATPase, and other factors of the sodium transport machinery.

The ENaC is a heteromultimer composed of $\alpha-, \beta-$, and $\gamma-$ subunits. ${ }^{9)}$ This channel is expressed in the apical membrane of $\mathrm{DCT} 2$ cells and the principal cells. The $\mathrm{ENaC}$, the rate-limiting step in $\mathrm{Na}^{+}$reabsorption in the distal nephron, ${ }^{10)}$ is rapidly induced in response to decreased distal $\mathrm{Na}^{+}$delivery $\left(\mathrm{Na}^{+}\right.$depletion) or

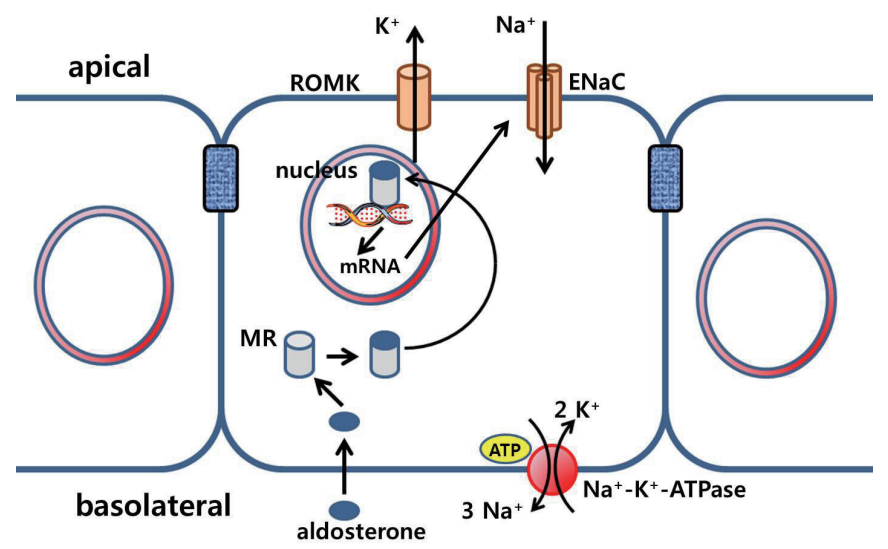

Fig. 2. The transepithelial sodium and potassium transport in the distal nephron.
A

Lumen

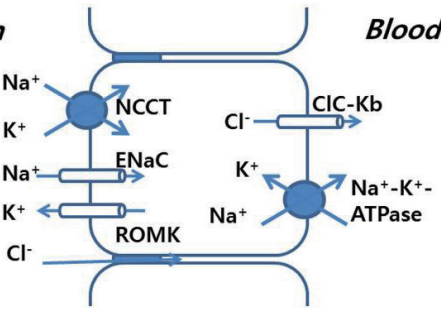

$\mathrm{B}$

Lumen

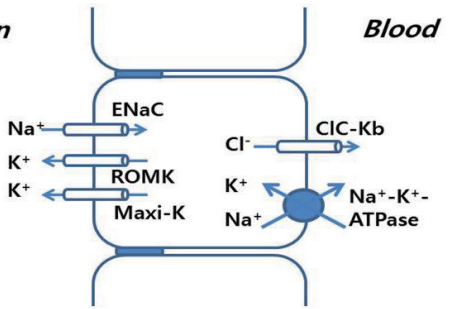

C

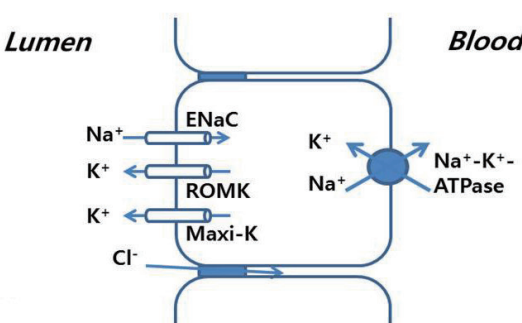

D

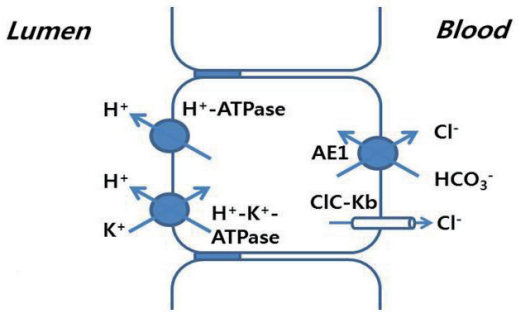

Fig. 1. Transporters and ion channel expressed in each segment of the distal nephon; late distal convoluted tubules (A), connecting tubules (B), principal cells in cortical collecting ducts (C), and $\alpha$-intercalated cells in cortical collecting ducts (D). 
increased aldosterone level. Another Na-transporter in DCT2, the thiazide-sensitive electroneutral $\mathrm{Na}^{+}-\mathrm{Cl}^{-}$cotransporter (NCCT), also respond to aldosterone as well.

In the kidney, $\mathrm{K}^{+}$is mainly secreted in the principal cells of the CNT and the CCD via two apical $\mathrm{K}^{+}$channels; a low-conductance ROMK and a large-conductance Maxi-K (BK). ${ }^{1,11)}$ The driving force for $\mathrm{K}^{+}$secretion is the lumen-negative potential difference generated by the reabsorption of $\mathrm{Na}^{+}$via ENaC. A high dietary $\mathrm{K}^{+}$intake stimulates aldosterone secretion and increases ROMK abundance at the apical membrane. The activity of the Maxi-K, a $\mathrm{Ca}^{2+}$-activated tetraethylammonium-sensitive channel, is increased by increased distal tubular flow rate. ${ }^{12,13)}$ The $\alpha$ intercalated cells in the CCD and MCD reabsorb $\mathrm{K}^{+}$via the apical $\mathrm{H}^{+}-\mathrm{K}^{+}$-ATPase. ${ }^{14)} \mathrm{A}$ high $\mathrm{K}^{+}$diet reduces the activity of the $\mathrm{H}^{+}-\mathrm{K}^{+}-$ ATPase and reduces $\mathrm{K}^{+}$reabsorption.

$\mathrm{Cl}^{-}$enters the cell via apical NCCT and exits via a basolateral $\mathrm{Cl}$ channel $(\mathrm{ClC}-\mathrm{Kb})^{15)}$ and a $\mathrm{KCl}$ cotransporter $(\mathrm{KCC} 4)^{16)}$ in DCT. The $\mathrm{CIC}-\mathrm{Kb}$ channel requires a $\beta$-subunit, barttin, which may enhance $\mathrm{CIC}-\mathrm{Kb}$ delivery to the basolateral membrane. ${ }^{17)}$ While the $\mathrm{CIC}-\mathrm{Kb}$ is expressed in the basolateral membrane of the CNT, the routes or channels involving apical transcellular transport of $\mathrm{Cl}$ - in this segment have not been identified. In the $\alpha$-intercalated cells, $\mathrm{Cl}^{-}$ enters across the basolateral membrane via a $\mathrm{Cl}^{-}-\mathrm{HCO}_{3}{ }^{-}$anion exchanger (AE1), which plays an important role in maintaining acid-base balance. ${ }^{18)}$ In addition, a $\mathrm{Na}^{+}$-independent $\mathrm{Cl}^{-}-\mathrm{HCO}_{3}$ exchanger, pendrin, is expressed in the apical membrane of the $\beta$ intercalated cells in the CNT and CCD and it may participate in $\mathrm{Cl}^{-}$ reabsorption. ${ }^{19)}$

Table 1. Classification of Pseudohypoaldosteronism (PHA)

\begin{tabular}{lll}
\hline Type & \multicolumn{1}{c}{ Genes } & \multicolumn{1}{c}{ Summary of clinical features } \\
\hline AD-PHA1 NR3C2 & Renal salt wasting, less severe form \\
& & Hyponatremia, hyperkalemia, metabolic acidosis \\
& & Elevated renin and aldosterone \\
AR-PHA1 & SCNN1A, & Systemic salt wasting, severe form \\
& SCNN1B & Hyponatremia, hyperkalemia, metabolic acidosis \\
& or SCNN1G & Elevated renin and aldosterone \\
& & Respiratory and dermatologic symptoms \\
PHA2 & WNK1, & Gordon syndrome, Familial hyperkalemic hypertension \\
& WNK4, & Autosomal dominant inheritance \\
& CUL3 & Hypertension, hyperkalemia, hyperchloremic metabolic \\
& acidosis \\
or KLHL3 & Low renin and variable aldosterone levels \\
PHA3 & Secondary to nephropathies or uropathies \\
& Hyponatremia, hyperkalemia, metabolic acidosis, \\
& Elevated renin and aldosterone, \\
& Low glomerular filtration rate
\end{tabular}

$A D$, autosomal dominant; $A R$, autosomal recessive

\section{Pseudohypoaldosteronism}

Pseudohypoaldosteronism (PHA) is a rare syndrome of mineralocorticoid resistance. $\mathrm{PHA}$ is a heterogeneous group of diseases and can be divided into two subgroups; PHA type 1 (PHA1) and type 2 (PHA2). PHA1 includes two different forms with different severity of the disease and phenotype: a systemic type of disease with autosomal recessive inheritance (sPHA1 or AR-PHA1) and a renal form with autosomal dominant inheritance (rPHA1 or AD-PHA 1). ${ }^{20-23)}$ In addition, there is a secondary form of $\mathrm{PHA}$, may be called as PHA type 3 (PHA3), which is characterized by transient mineralocorticoid resistance associated with various kidney diseases, mostly urinary tract infections and obstructive uropathies (Table 1).

The three mandatory clinical features of PHA are hyperkalemia, metabolic acidosis and elevated plasma aldosterone levels. Salt wasting is an additional feature in PHA1 and PHA3. While PHA1 and $\mathrm{PHA} 3$ are primarily salt losing syndromes, $\mathrm{PHA} 2$ is primarily a potassium retaining syndrome. ${ }^{22)}$

\section{Autosomal dominant pseudohypoaldosteronism type 1}

AD-PHA1 (OMIM \# 177735) is characterized by an isolated renal resistance to aldosterone, leading to renal salt wasting, dehydration and failure to thrive during infancy. ${ }^{1,20-25)}$ The main clinical symptom is insufficient weight gain due to chronic dehydration, and the cardinal laboratory abnormalities are hyponatremia, hyperkalemia, and metabolic acidosis despite elevated plasma renin activity and aldosterone levels. ${ }^{20-25}$ AD-PHA1 is caused by inactivating mutations in the NR3C2 gene encoding $\mathrm{MR}_{1}{ }^{26)}$ and heterozygous mutations have been detected in approximately $75 \%$ of patients with this disease. To date, more than 50 NR3C2 mutations have been described in association with AR-PHA $1 .{ }^{22)}$ Most of the patients have positive family history, but some sporadic cases also have been described. ${ }^{27-30)}$ There has been no report of linkage analysis study in pedigrees without pathogenic mutations in the NR3C2 gene, therefore the possibility of other candidate gene(s) remains to be unknown. Functional studies of a few of the NR3C2 mutations revealed that the mutations result in impaired ligand binding, DNA binding, or diminished trans-activation function. ${ }^{24,25,28}$ ${ }^{31}{ }^{32)}$ Therefore, some mutations result in haploinsufficiency from hypomorphic or null allele, while others may functions in a dominant negative function. In Korea, only one mutational 
report of a de novo heterozygous c.2146_2147insG mutation in NR3C2 has been described. ${ }^{30)}$

Reduced MR function results in $\mathrm{Na}^{+}$wasting and impairment in $\mathrm{K}^{+}$and $\mathrm{H}^{+}$secretion in the distal nephron, which leads to hyponatremia, hyperkalemia and metabolic acidosis. These electrolyte and acid-base imbalance usually manifests in neonates or early childhood. Exogenous mineralocorticoid treatment has no effect in patients with AD-PHA1, and patients usually respond well to sufficient enteral or parenteral salt supplementation. ${ }^{1,22,23)}$ Hyperkalemia is generally mild, and chronic ion exchange resin therapy to control hyperkalemia is rarely required. Interestingly, these abnormalities improve with increasing age in most cases, and the salt treatment becomes generally unnecessary by 2 to 3 years of age. ${ }^{1,22,23,26,27)}$ The reason for such spontaneous resolution of symptoms after infancy is not well understood, but it can be explained by (1) the change in diet from low-sodium human breast milk to higher salt diet, (2) maturation of $\mathrm{Na}^{+}$reabsorption function of the renal tubules with increasing age, (3) chronically upregulated renin-angiotensin-aldosterone system, and (4) replacement of distal sodium reabsorption by proximal parts of the tubules. ${ }^{20,}$ ${ }^{26,27)}$ However, high plasma aldosterone levels may persist even after normalization of other laboratory findings in most cases. ${ }^{27)}$ Therefore, the elevated serum aldosterone level was the only biochemical marker of AR-PHA1. However, reports from several families suggest that adult carriers of $N R 3 C 2$ mutations might also have normal levels of aldosterone. ${ }^{33)}$

When compared to AR-PHA1, the salt loss in AD-PHA1 is less severe, restricted to the kidneys, and improves spontaneously with age. Although mild in its course, it has been reported that AD-PHA1 can be associated with a high infant mortality rate. Geller et al ${ }^{27)}$ reported a number of unexplained deaths in infants at risk for $A D-P H A 1$, which suggests that $A D-P H A 1$ is potentially fatal to neonates. Therefore, early diagnosis and prophylactic salt supplementation for neonates at risk for AD-PHA1 is essential.

\section{Autosomal recessive pseudohypoaldosteronism type 1}

AR-PHA1 (OMIM \#264350) is caused by mutations of any of the three genes (SCNN1A, SCNN1B, and SCNN1G) encoding three subunits $(\alpha-, \beta-$, and $\gamma$-subunits, respectively) of the ENaC channel. ${ }^{34,35)}$ Patients typically manifest severe volume depletion associated with hypotension, failure to thrive, feeding difficulty within the first week of life. The laboratory tests reveal hyponatremia, hyperkalemia, metabolic acidosis, and marked elevation of plasma renin and aldosterone levels. ${ }^{21,36)}$ These renal symptoms are similar to those of AD-PHA1 but more severe in degree and earlier onset. Some patients present during pregnancy with polyhydramnios. ${ }^{37,38)} \mathrm{AR}-\mathrm{PHA} 1$ is not a renal tubule-restricted disease as AD-PHA1 but a systemic disease. Excessive salt wasting occurs via saliva and sweat as well as via urine. ${ }^{20)}$ High salt concentration in sweat may cause miliarialike rash on the face and trunk. ${ }^{39,40)}$ In addition, pulmonary manifestations associated with increased airway secretion, such as chronic cough and recurrent respiratory infections, frequently develop in older children ${ }^{36,41)}$ Newborn patients may develop respiratory distress also, although the incidence is rare. ${ }^{42,43)}$

AR-PHA 1 is a disease with a high mortality, especially early in life. ${ }^{36,44)}$ Therefore, sick infants should be treated urgently; saline infusion to correct volume depletion and hyponatremia, and ion exchange resin or emergency dialysis to control hyperkalemia. After recovery from acute crises, patients can be managed with high dose of oral salt supplements and chronic ion exchange resin therapy, and most patients require life-long salt supplementation. ${ }^{21)}$

\section{Other types of pseudohypoaldosteronism}

PHA2 (OMIM \# 145260), also called as Gordon syndrome or familial hyperkalemic hypertension, was first reported in $1964^{45)}$ and described as a syndrome by Gordon's group, in $1970 .{ }^{46)} \mathrm{PHA} 2$ is clinically characterized by hyperkalemia, hypertension, variable degree of hyperchloremic metabolic acidosis, and suppressed plasma renin activity with highly variable plasma aldosterone concentrations. These features are compatible with mirror image of those of Gitelman syndrome caused by loss-of-function mutations in the SLC12A3 gene encoding the thiazide sensitive NCCT. PHA2 is genetically heterogeneous and is associated with, at least, four disease-causing genes; WNK1 (type 2C, OMIM \#614492), WNK4 (type 2B, OMIM \#614491), CUL3 (type 2E, OMIM \#614496), and KLHL3 (type 2D, OMIM \#614495) genes ${ }^{47}$ ${ }^{48)}$ as well as a unknown gene (type 2A, OMIM \# 145260) located at chromosome 1q31-q42. All subtypes of PHA2 can be easily managed with low doses of thiazide diuretics. ${ }^{22)}$

PHA3 comprises transient and secondary forms of salt-losing states caused by various pathologies. Urinary tract infections and obstructive uropathies in neonates and young infants are the most frequent causes. ${ }^{22,49)}$ In addition, a number of drugs may cause resistance to aldosterone, leading to secondary 
PHA; drugs blocking ENaC activity (amiloride, triamterane, trimethoprim and pentamidine), drugs blocking MR function (spironolactone), drugs interfering with the renin-angiotensinaldosterone system (angiotensin converting enzyme inhibitors and the angiotensin II receptor antagonists), the cyclooxygenase inhibitors (inhibit renin release), heparin (inhibits aldosterone synthase), the beta-adrenergic antagonists (decrease $\mathrm{Na}^{+}-\mathrm{K}^{+}-$ ATPase activity and inhibit renin release), and the calcineurin inhibitors (cyclosporine A and tacrolimus). ${ }^{50,51)}$ Very rarely, major intestine resection or sweat gland dysfunction can also cause PHA3. ${ }^{22,49)}$

The clinical feature of PHA3 is almost same as that of ADPHA1. However, contrary to PHA1 and PHA2, the glomerular filtration rate is decreased in PHA3. This clinical and laboratory findings usually improve rapidly with medical or surgical treatment of the underlying cause and volume resuscitation. However, salt supplementation and control of hyperkalemia with ion exchange resin may be required in some patients. ${ }^{23)}$

\section{Conclusion}

PHA1, especially AR-PHA 1 , is a potentially life-threatening disorder in neonates and infants. Therefore, early diagnosis and treatment is essential for saving lives of the critically ill patients. The recent discovery of the underlying molecular pathophysiology in PHA has enabled better understanding of the physiological role of the distal nephron and the pathophysiology PHA. In addition, we, near future, can discover novel therapeutic target molecules and develop new drugs based on this understanding.

\section{Acknowledgement}

This study was supported by a grant of the Korean Health Technology R\&tD Project, Ministry of Health \& Welfare, Republic of Korea(A120017).

\section{References}

1. Ellison DH, Thomas CP. Chap. 16. Hereditary disorders of collecting duct sodium and potassium transport. In: Mount DB, Pollak MR, editor. Molecular and genetic basis of renal disease. Philadelphia, Saunders Elsevier, 2008:251-68.
2. Fuller PJ, Young MJ. Mechanisms of mineralocorticoid action. Hypertension 2005:46:1227-35.

3. Quinn SJ, Williams GH. Regulation of aldosterone secretion. Annu Rev Physiol 1988;50:409-26.

4. Spät A, Hunyady L. Control of aldosterone secretion: a model for convergence in cellular signaling pathways. Physiol Rev 2004;84:489-539.

5. Arriza JL, Weinberger C, Cerelli G, Glaser TM, Handelin BL, Housman DE et al. Cloning of human mineralocorticoid receptor complementary DNA: structural and functional kinship with the glucocorticoid receptor. Science 1987;237:268-75.

6. Funder JW, Pearce PT, Smith R, Smith AI. Mineralocorticoid action: target tissue specificity is enzyme, not receptor, mediated. Science $1988 ; 242: 583-5$

7. Quinkler $M$, Stewart PM. Hypertension and the cortisol-cortisone shuttle. J Clin Endocrinol Metab 2003;88:2384-92.

8. Mick VE, Itani OA, Loftus RW, Husted RF, Schmidt TJ, Thomas CP. The alpha-subunit of the epithelial sodium channel is an aldosteroneinduced transcript in mammalian collecting ducts, and this transcriptional response is mediated via distinct cis-elements in the 5'-flanking region of the gene. Mol Endocrinol 2001;15:575-88.

9. Alvarez de la Rosa D, Canessa CM, Fyfe GK, Zhang P. Structure and regulation of amiloride-sensitive sodium channels. Annu Rev Physiol 2000;62:573-94

10. Garty H, Palmer LG. Epithelial sodium channels: function, structure, and regulation. Physiol Rev 1997;77:359-96.

11. Wang W. Renal potassium channels: recent developments. Curr Opin Nephrol Hypertens 2004;13:549-55.

12. Woda CB, Bragin A, Kleyman TR, Satlin LM. Flow-dependent K+ secretion in the cortical collecting duct is mediated by a maxi-K channel. Am J Physiol Renal Physiol 2001;280:F786-93.

13. Liu W, Xu S, Woda C, Kim P, Weinbaum S, Satlin LM. Effect of flow and stretch on the $[\mathrm{Ca} 2+]$ i response of principal and intercalated cells in cortical collecting duct. Am J Physiol Renal Physiol 2003;285:F9981012.

14. Wingo CS, Smolka AJ. Function and structure of H-K-ATPase in the kidney. Am J Physiol 1995;269(1 Pt 2):F1-16.

15. Uchida S, Sasaki S. Function of chloride channels in the kidney. Annu Rev Physiol 2005;67:759-78.

16. Velázquez H, Silva T, Andújar E, Desir GV, Ellison DH, Greger R. The distal convoluted tubule of rabbit kidney does not express a functional sodium channel. Am J Physiol Renal Physiol 2001;280:F530-9.

17. Hayama A, Rai T, Sasaki S, Uchida S. Molecular mechanisms of Bartter syndrome caused by mutations in the BSND gene. Histochem Cell Biol 2003:119:485-93.

18. Shayakul $C_{1}$ Alper SL. Defects in processing and trafficking of the AE1 $\mathrm{Cl}^{-} / \mathrm{HCO}_{3}{ }^{-}$exchanger associated with inherited distal renal tubular acidosis. Clin Exp Nephrol 2004;8:1-11.

19. Wagner CA, Mohebbi N, Capasso G, Geibel JP. The anion exchanger 
pendrin (SLC26A4) and renal acid-base homeostasis. Cell Physiol Biochem 2011;28:497-504.

20. Geller DS. Mineralocorticoid resistance. Clin Endocrinol (Oxf) 2005; 62:513-20.

21. Hanukoglu A. Type I pseudohypoaldosteronism includes two clinically and genetically distinct entities with either renal or multiple target organ defects. J Clin Endocrinol Metab 1991;73:936-44.

22. Riepe FG. Pseudohypoaldosteronism. Endocr Dev 2013;24:86-95.

23. Kostakis ID, Cholidou KG, Perrea D. Syndromes of impaired ion handling in the distal nephron: pseudohypoaldosteronism and familial hyperkalemic hypertension. Hormones 2012;11:31-53.

24. Sartorato P, Lapeyraque AL, Armanini D, Kuhnle U, Khaldi Y, Salomon R, et al. Different inactivating mutations of the mineralocorticoid receptor in fourteen families affected by type I pseudohypoaldosteronism. J Clin Endocrinol Metab 2003;88:2508-17.

25. Sartorato $P$, Cluzeaud F, Fagart J, Viengchareun S, Lombès M, Zennaro MC. New naturally occurring missense mutations of the human mineralocorticoid receptor disclose important residues involved in dynamic interactions with deoxyribonucleic acid, intracellular trafficking, and ligand binding. Mol Endocrinol 2004;18:2151-65.

26. Geller DS, Rodriguez-Soriano J, Vallo Boado A, Schifter S, Bayer M, Chang SS, et al. Mutations in the mineralocorticoid receptor gene cause autosomal dominant pseudohypoaldosteronism type I. Nat Genet 1998;19:279-81.

27. Geller DS, Zhang J, Zennaro MC, Vallo-Boado A, Rodriguez-Soriano J, Furu L, et al. Autosomal dominant pseudohypoaldosteronism type 1: mechanisms, evidence for neonatal lethality, and phenotypic expression in adults. J Am Soc Nephrol 2006;17:1429-36.

28. Pujo L, Fagart J, Gary F, Papadimitriou DT, Claës A, Jeunemaître $X$, et al. Mineralocorticoid receptor mutations are the principal cause of renal type 1 pseudohypoaldosteronism. Hum Mutat 2007;28:33-40.

29. Riepe FG, Finkeldei J, de Sanctis L, Einaudi S, Testa A, Karges B, et al. Elucidating the underlying molecular pathogenesis of NR3C2 mutants causing autosomal dominant pseudohypoaldosteronism type 1. J Clin Endocrinol Metab 2006;91:4552-61.

30. Lee SE, Jung YH, Han KH, Lee HK, Kang HG, Ha IS, et al. A case of pseudohypoaldosteronism type 1 with a mutation in the mineralocorticoid receptor gene. Korean J Pediatr 2011;54:90-3.

31. Sartorato $P$, Khaldi Y, Lapeyraque AL, Armanini D, Kuhnle U, Salomon R, et al. Inactivating mutations of the mineralocorticoid receptor in Type I pseudohypoaldosteronism. Mol Cell Endocrinol 2004;217:119-25.

32. Tajima T, Kitagawa H, Yokoya S, Tachibana K, Adachi M, Nakae J, et al. A novel missense mutation of mineralocorticoid receptor gene in one Japanese family with a renal form of pseudohypoaldosteronism type 1. J Clin Endocrinol Metab 2000;85:4690-4.

33. Riepe FG, Krone N, Morlot M, Peter M, Sippell WG, Partsch CJ. Autosomal-dominant Pseudohypoaldosteronism type 1 in a Turkish family is associated with a novel nonsense mutation in the human mineralocorticoid receptor gene. J Clin Endocrinol Metab 2004;89:2150-
34. Chang SS, Grunder S, Hanukoglu A, Rösler A, Mathew PM, Hanukoglu I, et al. Mutations in subunits of the epithelial sodium channel cause salt wasting with hyperkalaemic acidosis, pseudohypoaldosteronism type 1. Nat Genet 1996;12:248-53.

35. Strautnieks SS, Thompson RJ, Gardiner RM, Chung E. A novel splicesite mutation in the gamma subunit of the epithelial sodium channel gene in three pseudohypoaldosteronism type 1 families. Nat Genet 1996;13:248-50.

36. Oberfield SE, Levine LS, Carey RM, Bejar R, New MI. Pseudohypoaldosteronism: multiple target organ unresponsiveness to mineralocorticoid hormones. J Clin Endocrinol Metab 1979;48:228-34.

37. Greenberg D, Abramson O, Phillip M. Fetal pseudohypoaldosteronism: another cause of hydramnios. Acta Paediatr 1995;84:582-4.

38. Narchi H, Santos M, Kulaylat N. Polyhydramnios as a sign of fetal pseudohypoaldosteronism. Int J Gynaecol Obstet 2000;69:53-4.

39. Urbatsch A, Paller AS. Pustular miliaria rubra: a specific cutaneous finding of type I pseudohypoaldosteronism. Pediatr Dermatol 2002; $19: 317-9$

40. Martín JM, Calduch L, Monteagudo C, Alonso V, Garcia L, Jordá E. Clinico-pathological analysis of the cutaneous lesions of a patient with type I pseudohypoaldosteronism. J Eur Acad Dermatol Venereol 2005;19:377-9.

41. Kerem E, Bistritzer T, Hanukoglu A, Hofmann T, Zhou Z, Bennett W, et al. Pulmonary epithelial sodium-channel dysfunction and excess airway liquid in pseudohypoaldosteronism. N Engl J Med 1999;341:156-62.

42. Malagon-Rogers M. A patient with pseudohypoaldosteronism type 1 and respiratory distress syndrome. Pediatr Nephrol 1999;13:484-6.

43. Akçay A, Yavuz T, Semiz S, Bundak R, Demirdöven M. Pseudohypoaldosteronism type 1 and respiratory distress syndrome. J Pediatr Endocrinol Metab 2002;15:1557-61.

44. Rösler A. The natural history of salt-wasting disorders of adrenal and renal origin. J Clin Endocrinol Metab 1984;59:689-700.

45. Paver WK, Pauline GJ. Hypertension and hyperpotassaemia without renal disease in a young male. Med J Aust 1964;2:305-6.

46. Gordon RD, Geddes RA, Pawsey CG, O'Halloran MW. Hypertension and severe hyperkalaemia associated with suppression of renin and aldosterone and completely reversed by dietary sodium restriction. Australas Ann Med 1970;19:287-94.

47. Wilson FH, Disse-Nicodème $S$, Choate KA, Ishikawa K, Nelson-Williams C, Desitter I, et al. Human hypertension caused by mutations in WNK kinases. Science 2001;293:1107-12.

48. Boyden LM, Choi M, Choate KA, Nelson-Williams CJ, Farhi A, Toka HR, et al. Mutations in Kelch-like 3 and Cullin 3 cause hypertension and electrolyte abnormalities. Nature 2012;482:98-102.

49. Bülchmann G, Schuster T, Heger A, Kuhnle U, Joppich I, Schmidt H. Transient pseudohypoaldosteronism secondary to posterior urethral valves - a case report and review of the literature. Eur J Pediatr Surg 
2001;11:277-9.

50. DuBose TD Jr. Molecular and pathophysiologic mechanisms of hyperkalemic metabolic acidosis. Trans Am Clin Climatol Assoc 2000;111:12233.
51. Bogdanović R, Stajić N, Putnik J, Paripović A. Transient type 1 pseudohypoaldosteronism: report on an eight-patient series and literature review. Pediatr Nephrol 2009;24:2167-75. 